\title{
Observation of semiannual and annual oscillation in equatorial middle atmospheric long term temperature pattern
}

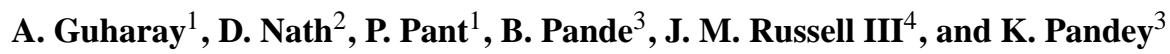 \\ ${ }^{1}$ Aryabhatta Research Institute of observational scienES (ARIES), Nainital, India \\ ${ }^{2}$ National Atmospheric Research Laboratory (NARL), Gadanki, India \\ ${ }^{3}$ Dept. of Physics, DSB Campus, Kumaun University, Nainital, India \\ ${ }^{4}$ Center for Atmospheric Sciences, Hampton University, Hampton, VA, USA
}

Received: 8 April 2009 - Revised: 29 October 2009 - Accepted: 12 November 2009 - Published: 16 November 2009

\begin{abstract}
Extensive measurement of middle atmospheric temperature with the help of lidar data of more than 10 years (1998-2008) and TIMED/SABER data of 7 years (20022008), has been carried out from a low latitude station, Gadanki, India $\left(13.5^{\circ} \mathrm{N}, 79.2^{\circ} \mathrm{E}\right)$, which exhibits the presence of semiannual oscillation (SAO) and annual oscillation $(\mathrm{AnO})$. The AnO component is stronger in the mesospheric region $(80-90 \mathrm{~km})$ and the $\mathrm{SAO}$ is dominant at stratospheric altitudes $(30-50 \mathrm{~km})$. Overall, the $\mathrm{AnO}$ possesses higher amplitude $\sim 6-7 \mathrm{~K}$, and the $\mathrm{SAO}$ shows less amplitude $\sim 1-$ $2 \mathrm{~K}$. The AnO present at $90 \mathrm{~km}$ finds crest near summer solstice, and the same at $80 \mathrm{~km}$ shows peak near winter solstice with a downward progression speed $\sim 1.7 \mathrm{~km} /$ month. The SAO propagates downward with an average phase speed $\sim 9 \mathrm{~km} /$ month and phase maximizes around equinox and solstice at 50 and $30 \mathrm{~km}$, respectively. The observed SAO has also shown seasonal asymmetry in peaks.
\end{abstract}

Keywords. Meteorology and atmospheric dynamics (Middle atmosphere dynamics; Waves and tides; Instruments and techniques)

\section{Introduction}

Middle atmospheric dynamics is strongly controlled by long periodicity wave features, e.g. semiannual oscillation (SAO) and annual oscillation (AnO) other than short period gravity waves, planetary waves and atmospheric tides. The period of oscillation for the $\mathrm{SAO}$ is $\sim 6$ months, and for the $\mathrm{AnO}$ it is $\sim 12$ months, although the actual values of these oscillations may change a little in the reality due to wave-wave, wavemean flow interaction. For the last few decades, a number of

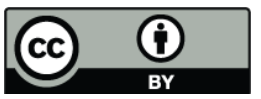

Correspondence to: A. Guharay (amitava@aries.res.in) observations all around the globe have been carried out using several ground-based and space-based instruments to figure out these oscillations (e.g. Clancy et al., 1994; Shepherd et al., 2004).

It is important to mention that the SAO was first observed by Reed (1965) using rocket based probing of stratospheric wind over an equatorial site. Groves (1972) carried out investigation of the $\mathrm{AnO}$ and $\mathrm{SAO}$ components in wind in the range of 60 and $130 \mathrm{~km}$ using zonal wind measurements obtained through meteor radars and rockets. Using Solar Mesosphere Explorer (SME) temperature data, Clancy et al. (1994) observed the SAO and AnO in low and mid latitude, respectively in mesospheric region and they inferred that both oscillations are caused mostly by meridional circulation and associated adiabatic heating, which affect the mesospheric global temperatures more than the stratospheric temperatures. From the satellite-based Wind Imaging Interferometer (WINDII) and the ground-based airglow measurement instruments derived zonal mean temperature, Shepherd et al. (2004) investigated the characteristics and properties of the SAO and AnO over low and mid latitude sites. $\mathrm{Xu}$ et al. (2007) studied seasonal, altitudinal and latitudinal variability of the SAO, AnO and quasi-biennial oscillation (QBO) with the help of zonal mean temperature data of Sounding of the Atmosphere using Broadband Emission Radiometry (SABER) instrument onboard the ThermosphereIonosphere-Mesosphere Energetics and Dynamics (TIMED) satellite in the stratosphere and mesosphere region. Zhao et al. (2007) studied the properties of the SAO and AnO using $\mathrm{O}_{2}$ (0-1) and $\mathrm{OH}(6-2)$ emissions with the help of airglow imager instrument from a low latitude station, Maui, USA $\left(20.8^{\circ} \mathrm{N}\right)$.

In our present work, we have analyzed long term temperature data obtained through lidar from an equatorial site, Gadanki $\left(13.5^{\circ} \mathrm{N}, 79.2^{\circ} \mathrm{E}\right)$, India and space based TIMED/SABER data to characterize the middle atmospheric

Published by Copernicus Publications on behalf of the European Geosciences Union. 
SAO and AnO. We have used lidar data during March, 1998 to December, 2008 of total 930 nights and SABER data during the interval of February, 2002 to December, 2008 of total 763 nights. Both data have revealed significant variability of the $\mathrm{SAO}$ and $\mathrm{AnO}$ in the long term variation pattern.

\section{Instruments for observation}

\subsection{Lidar}

The lidar in Gadanki was installed in March 1998, under Indo-Japanese collaboration program. It utilizes Nd:YAG pulsed laser transmitter with two receiving telescopes (Rayleigh and Mie), data acquisition and processing subsystems. The photon counts received by the Rayleigh telescope are used to derive temperature profiles using the almost similar algorithm of Hauchecorne and Chanin (1980) with time resolution of $250 \mathrm{~s}$ and height resolution of $300 \mathrm{~m}$. Details of the data analysis and the system configuration is given elsewhere (Siva Kumar et al., 2003). Most recent observation from the same site, using comparative lidar and SABER temperature, Kishore Kumar et al. (2008) (hereafter referred as KK08) concluded that the Gadanki lidar is very reliable for accurate temperature measurements in the range $\sim 35-80 \mathrm{~km}$ with an accuracy $0.5-1.5 \mathrm{~K}$ in the stratosphere and $2-3 \mathrm{~K}$ in the mesosphere.

\subsection{SABER}

The SABER instrument is placed onboard TIMED satellite, at an altitude of $625 \mathrm{~km}$, with an inclination of about $74.1^{\circ}$ with the equator and it can perform a good diurnal coverage over a particular site on the earth in $\sim 60$ days (yaw period). The SABER data is available since January 2002 from the website http://saber.gats-inc.com/. The viewing geometry of the SABER enables it to measure wave activities (tides, planetary waves etc.). It measures infrared limb emissions of carbon dioxide, water vapor, ozone, nitric oxide, molecular oxygen and hydroxyl from $1.27 \mu \mathrm{m}$ to $15.2 \mu \mathrm{m}$ (Russell et al., 1999). Detailed comparative results with other instruments are given by Mertens et al. (2004). Recently, Remsberg et al. (2008) has shown that the version1.07 SABER data is very efficient to perform temperature measurement with uncertainty in the order of $1-3 \mathrm{~K}$ in lower stratosphere, $\sim 1 \mathrm{~K}$ near stratopause, and $\sim 2 \mathrm{~K}$ in middle atmosphere. It is also inferred from their study that the SABER can be utilized to determine diurnal-interannual-scale temperatures, especially for upper mesosphere and lower thermosphere region. We have used version 1.07 level2A dataset for the present study.

\section{Data analysis and results}

The lidar data collected in Rayleigh mode over long term ( $>10$ years) observation period is used to estimate the tem- perature in the range $27-80 \mathrm{~km}$, where the lower limit is set to get rid of Mie contribution by atmospheric aerosols, and the higher limit is decided because of large error in temperature estimate due to low density and less backscattered signal. In the present work, we have taken nightly average temperature profiles to reduce the standard error and ultimately the monthly average profile has been calculated from all the night profiles of the concerned month at 3 altitudes, 80,50 and $30 \mathrm{~km}$ for wave analysis, which represent the mesospheric and stratospheric temperature signatures. In this averaging process, the short term and tidal variability are also reduced. In this context, it should be mentioned that KK08 obtained higher uncertainty in the Gadanki lidar temperature below $\sim 35 \mathrm{~km}$ in comparison with SABER. From the difference (lidar and SABER) contour (Fig. 5 of KK08) it is obvious that around $\sim 30 \mathrm{~km}$ the pattern is most consistent throughout the year except June and July months, although the difference is highest there. This result implies that $\sim 30 \mathrm{~km}$, the lidar data can be utilized to carry out monthly/yearly scale oscillation characteristics. Data gaps are observed during certain times of the years as evident from Fig. $1 b$.

For the SABER, nocturnal profiles are obtained during the overpass of the TIMED satellite over the observational site within the square grid of latitude range $10-16^{\circ} \mathrm{N}$ and longitude range $76-82^{\circ}$ E. Here the SABER data have been collected only for nights to reduce the tidal and planetary wave influence on the derived oscillation characteristics and also for achieving good coincidence between these two observations. The monthly average profiles are calculated in the same way as the lidar for the altitudes $90,80,50$ and $30 \mathrm{~km}$ from the daily mean profiles. Advantage of the SABER data is more evenly-spaced sampling of observation unlike the lidar (Fig. 1).

Figure 1 describes the contours of the monthly mean long term temperature pattern of SABER and lidar in the altitude range $25-95$ and $30-80 \mathrm{~km}$, respectively. Significant variability is observed in the stratosphere and mesosphere in both lidar and SABER. More patches evident from the contours at higher altitude indicate that variability increases with altitude. The SABER range of variability is less than that of the lidar. Semiannual variability is very prominent at $45-55 \mathrm{~km}$ and annual variability is also conspicuous at $65-75 \mathrm{~km}$ in the SABER mean temperature. This variability is also present in the lidar data, but the pattern is not that much prominent unlike the SABER due to more data gaps. Hence for interpreting the dominant wave components, we need to perform further spectral analysis, which is carried out in next few sections.

Detailed data statistics in terms of observation nights has been shown in Fig. 2 for the lidar (1998-2008) and SABER (2002-2008) with respect to the corresponding months. The lidar observations are less during monsoon season in comparison with the winter months due to unfavorable weather conditions, whereas the SABER overpasses are very less during 


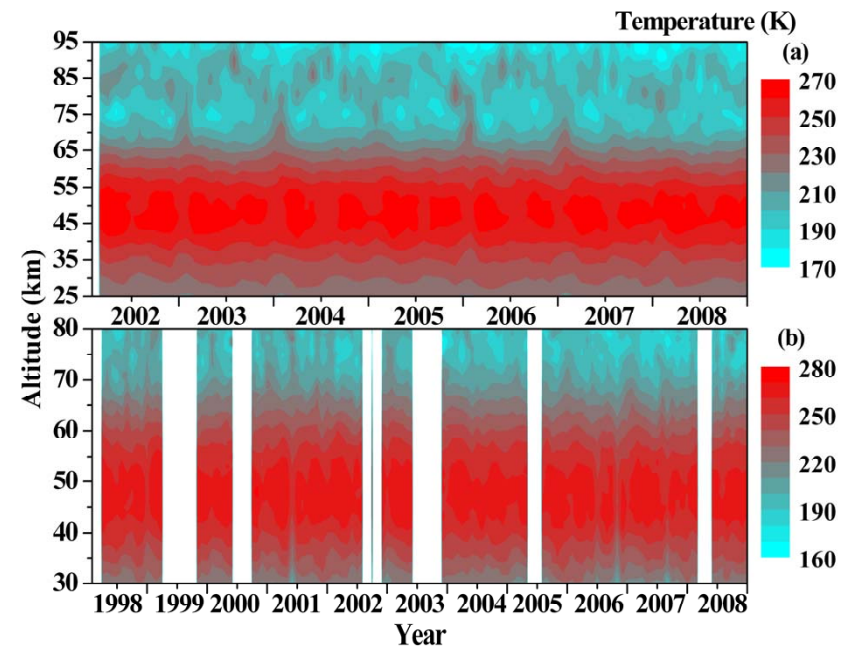

Fig. 1. Contour plot of monthly mean temperatures with respect to altitude and corresponding month of the years for (a) SABER and (b) lidar.

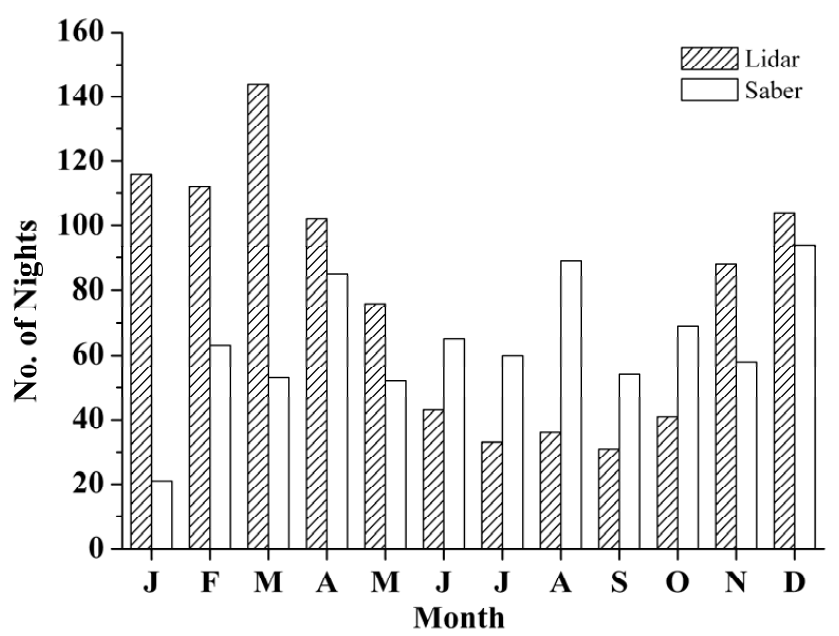

Fig. 2. Total number of observation nights for lidar (1998-2008) and SABER (2002-2008).

January and relatively good coverage is seen in other times. The nocturnal lidar observation consists of more than 50 vertical temperature profiles per night most of the time. On average, $65 \%$ nights of the total observations utilize 2 profiles and $35 \%$ nights utilize 1 profile as a proxy for nocturnal temperature of SABER.

For better characterization of the long period wave features in the middle atmospheric thermal structure, we have carried out Lomb-Scargle periodogram analysis using Hamming window (to identify dominant periodicity and suppress insignificant components by minimizing spectral leakage) on the observation data and the normalized power spectra are shown in Fig. 3. Horizontal lines in the plot show the $99.9 \%$ confidence level. The result of periodogram analysis of the

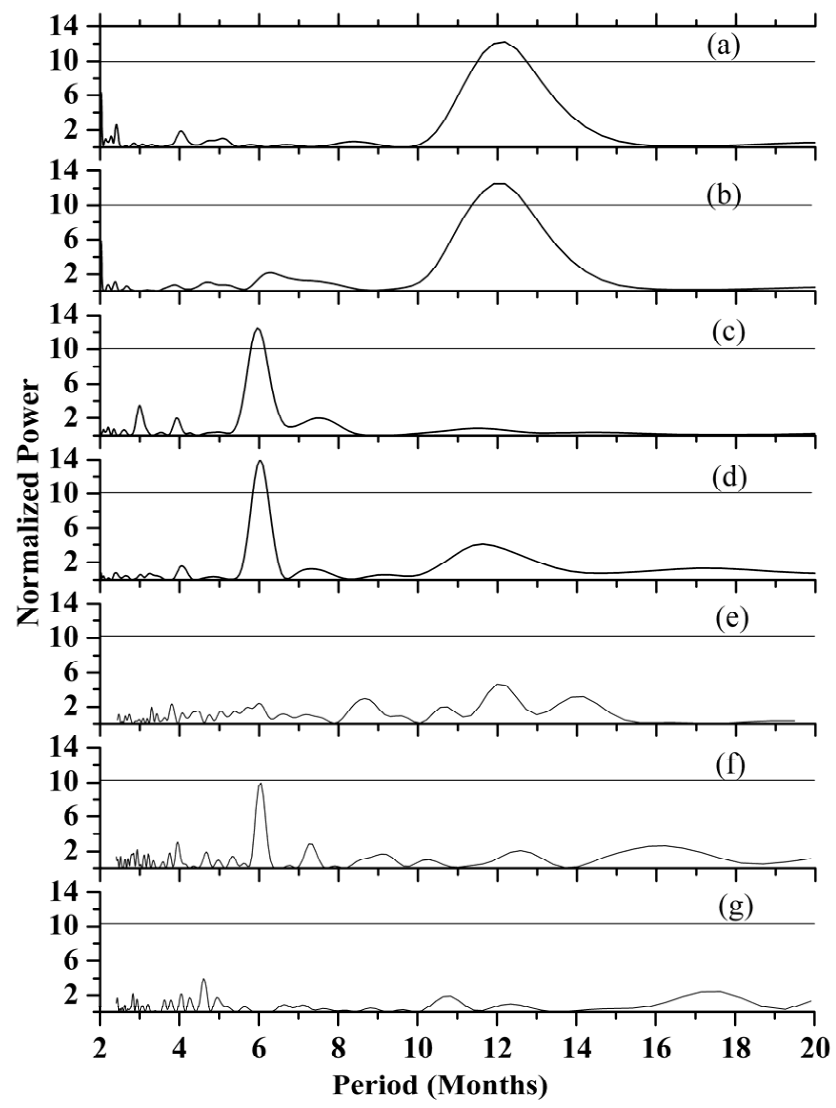

Fig. 3. Lomb-Scargle periodogram using Hamming window of SABER data (February 2002-December 2008) for (a) $90 \mathrm{~km}$, (b) $80 \mathrm{~km}$, (c) $50 \mathrm{~km}$, (d) $30 \mathrm{~km}$ and the same for lidar (e) $80 \mathrm{~km}$, (f) $50 \mathrm{~km}$, (g) $30 \mathrm{~km}$. Horizontal lines represent $99.9 \%$ confidence level.

SABER has revealed prominent long term oscillation features. The strong component of AnO ( 12 month) is observed in $90 \mathrm{~km}$ and $80 \mathrm{~km}$ temperature patterns. Remarkably different phenomenon is conspicuous in 50 and $30 \mathrm{~km}$ temperature data, where SAO is the dominant one. The lidar data reveals a prominent SAO component at $\sim 50 \mathrm{~km}$. There is no evident wave periodicity at other altitudes (80 and $30 \mathrm{~km}$ ), may be due to less reliability in representing true thermal structure of the middle atmosphere during monsoon period (KK08) because of significant data gaps, which leads to less confidence in determination of the oscillation peaks in the power spectrum by producing non-Gaussian noise.

The lidar data (after removing outlier data) of eleven years span and the SABER data of 7 years have been folded into one year period and the monthly average temperatures are computed, which is plotted in Fig. 4 with respect to corresponding months. The vertical bars represent standard errors of the mean temperatures. Best sinusoidal wave fit (weighted by the standard errors) analysis similar to Guharay et al. (2008) has been performed to deduce period and amplitude of oscillations at $90,80,50$ and $30 \mathrm{~km}$ data. Results of 


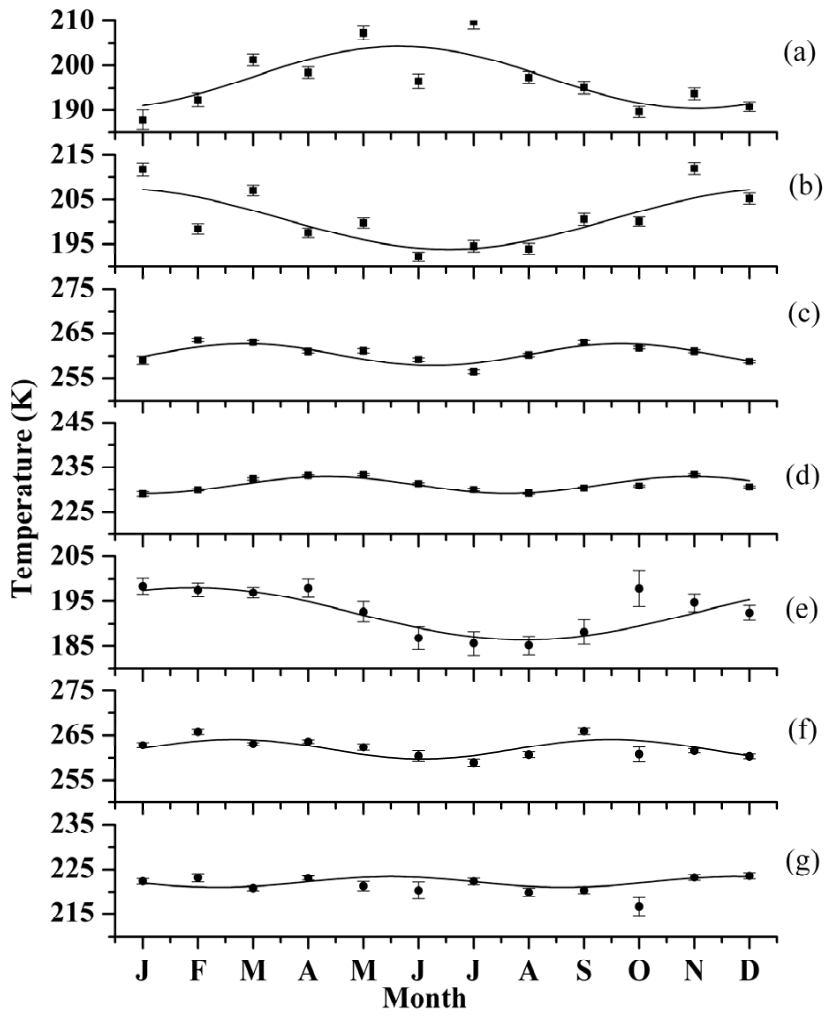

Fig. 4. Folded dataset of monthly mean into one year span with best sinusoidal fit for SABER (a) $90 \mathrm{~km}$, (b) $80 \mathrm{~km}$, (c) 50 , (d) $30 \mathrm{~km}$ and the same for lidar (e) $80 \mathrm{~km}$, (f) $50 \mathrm{~km}$, (g) $30 \mathrm{~km}$, shown with filled circles. Vertical bars show standard errors. Solid line is the best fit model.

the least square weighted sinusoidal fit have been shown in Table 1. Calculated vertical phase speed of the SAO comes out to be $\sim 6.8$ and $11.1 \mathrm{~km} /$ month for lidar and SABER, respectively. Vertical phase speed for the AnO comes out to be $\sim 1.7 \mathrm{~km} /$ month from SABER. It is evident from the result (amplitude) that the AnO is stronger in the mesosphere than the $\mathrm{SAO}$ in the stratosphere. The $\mathrm{SAO}$ at $50 \mathrm{~km}$ peaks around equinox and at $30 \mathrm{~km}$ it shifts in order of $\sim 2-3$ months, i.e. near solstice. The observed $\mathrm{AnO}$ at 90 and $80 \mathrm{~km}$ shows crests near summer and winter solstices, respectively.

A band pass digital filter is used with cut offs at 10 and 14 months, centered around 12 month, to figure out the AnO component in the time series monthly mean data ( $\Delta T \sim$ deviation from the mean nocturnal temperature computed over whole observation period) at 90 and $80 \mathrm{~km}$, as the $\mathrm{AnO}$ is conspicuous at those altitudes from periodogram and best wave fit analysis described before. Similarly, data at 50 and $30 \mathrm{~km}$ has undergone another band pass filter of cut offs at $\sim 4$ and 8 months, centered around 6 month, to characterize the SAO in stratosphere, shown in Fig. 5. The SABER profiles exhibit more evident signatures of the SAO and AnO in comparison with lidar ones. From the figure it is clear that the AnO in mesosphere exhibits larger amplitude in compari-

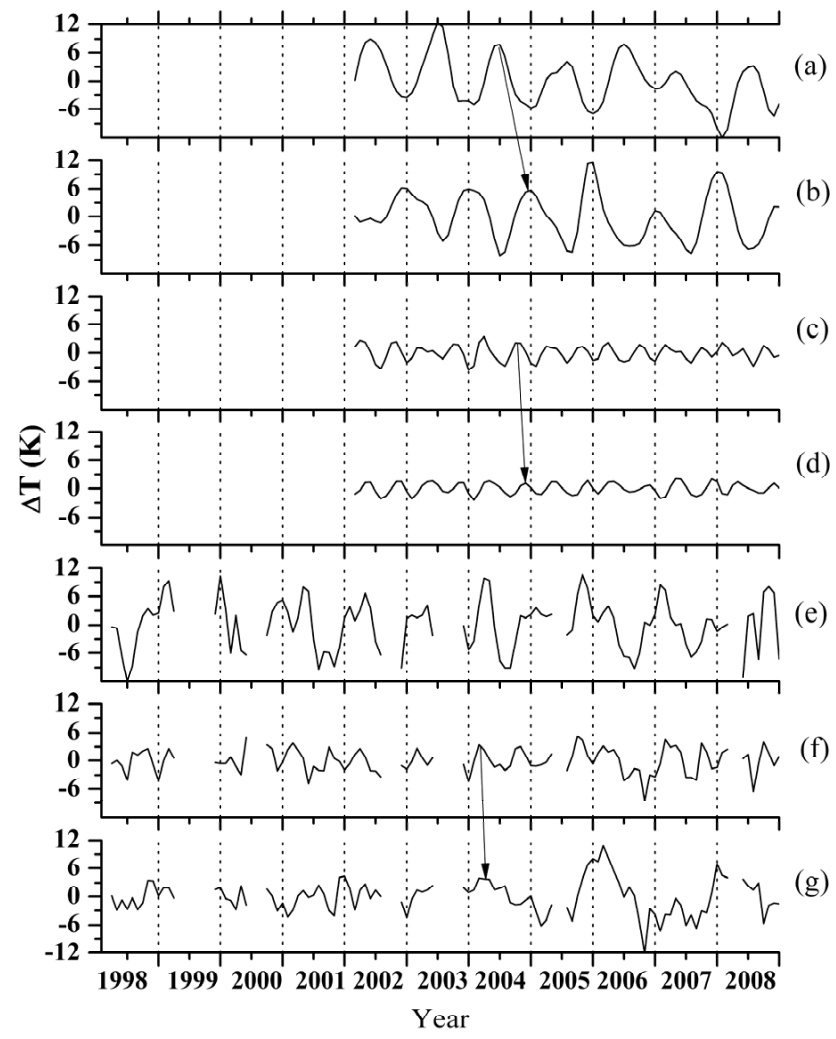

Fig. 5. Filtered monthly average $\Delta T(\sim$ deviation of monthly mean from long term mean temperature) after passing through a band pass filter with 10 and 14 months cut off for SABER (a) $90 \mathrm{~km}$, (b) $80 \mathrm{~km}$ and lidar (e) $80 \mathrm{~km}$. The same with a filter of 4 and 8 months cut off, for SABER (c) $50 \mathrm{~km}$ (d) $30 \mathrm{~km}$ and lidar (f) $50 \mathrm{~km}$, (g) $30 \mathrm{~km}$. The arrows show downward phase progression.

son with the SAO in stratosphere for both (lidar and SABER) data, similar to the best wave fit results. Again, the observed $\mathrm{AnO}$ at $90 \mathrm{~km}$ is almost in opposite phase with respect to that at $80 \mathrm{~km}$, which is also evident in the best fit results (phase difference $\sim 157^{\circ}$ ). Earlier, Shepherd et al. (2004) showed the nature of global scale variability of the SAO and $\mathrm{AnO}$ by utilizing the WINDII data and they obtained phase difference between 87 and $75 \mathrm{~km}$, around $\sim 45$ days for the $\mathrm{AnO}$ at $15^{\circ} \mathrm{N}$ latitude. Comparatively higher phase difference in the present study may be due to regional climatological effect of the atmospheric waves. Downward phase progression has been shown by the arrows for both $\mathrm{AnO}$ and SAO components. It should be mentioned that in the case of SAO, the first peak (spring equinox) is higher than the second (fall equinox) one almost all the time.

\section{Discussions}

Present observations from the ground based lidar and the satellite based SABER temperature data over a long period of time (1998-2008), have unveiled long term wave activities 
Table 1. Wave parameters derived after best sinusoidal fit to SABER and lidar data.

\begin{tabular}{|c|c|c|c|c|c|c|}
\hline Altitude $(\mathrm{km})$ & Period (month) & $\begin{array}{c}\text { SAO } \\
\text { Amplitude (K) }\end{array}$ & Phase (day) & Period (month) & $\begin{array}{c}\text { AnO } \\
\text { Amplitude (K) }\end{array}$ & Phase (day) \\
\hline 90 (SABER) & - & - & - & $10.8 \pm 1.9$ & $7.0 \pm 1.8$ & $161.2 \pm 7.4$ \\
\hline 80 (LIDAR) & - & - & - & $12.0 \pm 1.4$ & $5.8 \pm 1.0$ & $61.6 \pm 2.7$ \\
\hline 80 (SABER) & - & - & - & $12.1 \pm 4.8$ & $6.8 \pm 2.5$ & $4.3 \pm 11.6$ \\
\hline 50 (LIDAR) & $6.8 \pm 0.6$ & $2.2 \pm 0.8$ & $78.5 \pm 5.1$ & - & - & - \\
\hline 50 (SABER) & $6.8 \pm 0.4$ & $2.4 \pm 0.5$ & $85.5 \pm 5.2$ & - & - & - \\
\hline 30 (LIDAR) & $6.2 \pm 0.8$ & $1.2 \pm 0.6$ & $168.4 \pm 12.3$ & - & - & - \\
\hline 30 (SABER) & $6.6 \pm 0.6$ & $1.9 \pm 0.3$ & $165.3 \pm 10.7$ & - & - & - \\
\hline
\end{tabular}

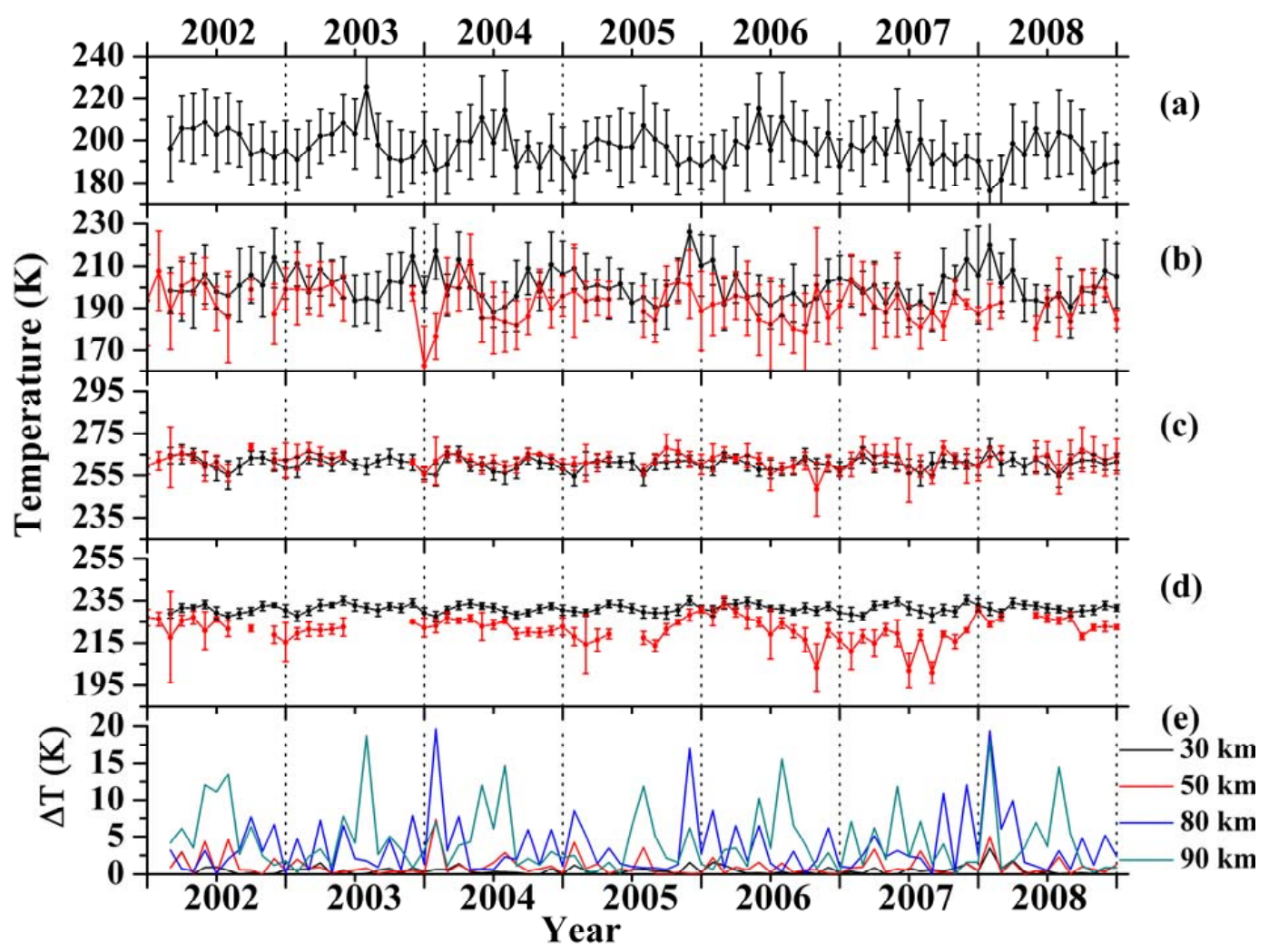

Fig. 6. Monthly mean temperatures (filled circle with solid line) along with standard deviations (vertical bars) for SABER (black) and lidar (red) at (a) $90 \mathrm{~km}$, (b) $80 \mathrm{~km}$, (c) $50 \mathrm{~km}$, (d) $30 \mathrm{~km}$. (e) Monthly mean absolute temperature deviation $(\Delta T)$ between diurnal and nocturnal temperature for SABER.

in multi-year temperature pattern. Prominent signature of the $\mathrm{SAO}$ and $\mathrm{AnO}$ is embedded in the equatorial middle atmosphere as obtained from our present study. One interesting feature is that mesospheric region is dominated by the AnO, while the SAO is evident in stratospheric altitudes, although both components are present simultaneously in the middle atmosphere. The SABER results match reasonably well with the lidar ones. Our results evince that the SAO and AnO possess amplitude in the range of $\sim 1-2 \mathrm{~K}$ and 6-7 K, respectively, which implies stronger AnO in comparison with the $\mathrm{SAO}$ over the long term observation period. The AnO at
$90 \mathrm{~km}$ peaks during summer solstice, and at $80 \mathrm{~km}$ it shifts by nearly 6 months, i.e. around winter solstice. At $50 \mathrm{~km}$ the SAO exhibits its crest around equinox and at $30 \mathrm{~km}$ the peak is observed near solstice ( $\sim 3$ months shift). Simultaneous presence of the $\mathrm{SAO}$ and $\mathrm{AnO}$ in the middle atmosphere indicates that there may be some relationship between these long-period wave components. The observed AnO at mesosphere and lower thermosphere altitudes in the present case is possibly a manifestation of interaction between the SAO and other wave components or mean wind in the stratosphere. An important issue regarding the Gadanki lidar results needs to 
be discussed is less number of daily observations available during monsoon and fall equinox months (June-October), as evident from Fig. 2, which was also pointed out by KK08 previously. The scarcity in the data poses additional uncertainty in determination of such kind of periodic features.

The observed SAO and AnO in the stratosphere and mesosphere are generated due to several reasons, e.g. variation of solar zenith angle with the season and incident solar flux change throughout the year. Tides and gravity waves and their mutual interaction can be an important factor for modification of such seasonal scale variability (Gurubaran and Rajaram, 2001). Kelvin waves can be an important contributor for the generation of the stratospheric SAO as suggested by Hirota (1978). Another important driver for the SAO is QBO, which is reported by several investigators in temperature and wind (e.g., Shepherd et al., 2005; Ratnam et al., 2008). To verify the effect of planetary waves and tides on our observed SAO and AnO variability, we have estimated the standard deviations (considered as a proxy for planetary waves) of the monthly mean temperatures for both lidar and SABER and the absolute deviation (considered as a proxy for tidal activity and gravity waves) of the diurnal and nocturnal average temperatures for the SABER throughout the long term observation period at the specified altitudes, which is shown in Fig. 6. The vertical bars of Fig. 6a-d represent the standard deviations of the monthly means. From the plot it is evident that the standard deviation increases with the altitude, which implies higher influence of the planetary wave activities with growing altitude. Maximum standard deviation is observed to be $\sim 25 \mathrm{~K}$ at $90 \mathrm{~km}$ in the SABER. Significant variability of the planetary waves as revealed by our results, may be considered to modify the long-term oscillation features to some extent at higher altitude. Figure 6e shows the absolute deviation profile of the diurnal and nocturnal mean temperature for SABER during 2002-2008. Larger deviations at higher altitude may indicate tidal amplitude (mainly migrating diurnal tide) or large-scale gravity waves with periodicity of few hours, which increases with height to cause a maximum difference of $\sim 20 \mathrm{~K}$. Since amplitude of the diurnal tide is nearly zero at $\pm 15^{\circ}$ latitude (Forbes and Gillette, 1982; Clancy et al., 1994), hence these differences could be attributed mainly to gravity waves for our location $\left(13.5^{\circ} \mathrm{N}\right)$. Also random nature of appearance of the higher magnitude peaks (especially at 90 and $80 \mathrm{~km}$ ) within the whole time span rules out the dominant influence of tides. We have further minimized the insignificant influence of tides and gravity waves by selecting only nighttime data for both observations throughout the analysis procedure. Recently, Xu et al. (2007) studied the possible effect of diurnal tide on the mesospheric SAO using the SABER 4 year (2002-2006) database at the equator, where the amplitude of the diurnal tide maximizes and they concluded that the SAO is the manifestation of the mean temperature rather than modification by the diurnal tide.

Ann. Geophys., 27, 4273-4280, 2009
In this context, it should be noted that there is a systematic difference between SABER and lidar derived monthly mean temperatures at 80 and $30 \mathrm{~km}$, may be due to different retrieval techniques or principles utilized for temperature estimate from these two instruments. Details of the difference between the Gadanki lidar and SABER temperatures and the probable reasons below $35 \mathrm{~km}$ and above $72 \mathrm{~km}$ are discussed in the most recent literature by Guharay et al. (2009). This disparity does not put any major constraint for finding out long period oscillations (few months or years), as it is consistent over time. Another important point should be mentioned that although the difference of the lidar and SABER temperatures at 80 and $30 \mathrm{~km}$ are comparable to the derived amplitude of the SAO and $\mathrm{AnO}$, it would not effect considerably on the estimates because of independent utilization of two datasets for calculating the same.

It can be noted that Zhao et al. (2007) (their Table 2) compared the SAO and AnO amplitudes obtained from various temperature observations at 87 and $94 \mathrm{~km}$, performed by several investigators at low latitude stations $\left(20-21^{\circ}\right)$ in both hemispheres and they found the SAO amplitudes varies in the range $2.1-5.8 \mathrm{~K}$ and for the $\mathrm{AnO}$ it is in the order of 0.3$3.1 \mathrm{~K}$. The range of variability for the SAO partially overlaps with our observed one, but at the same time their obtained the AnO amplitudes are much lower than ours. This discrepancy of the observed results is possibly due to the effect of tidal aliasing in the case of earlier observations carried out from the extra-tropical latitude regions. Also Taylor et al. (2005) found the SAO amplitude of $\sim 5-6 \mathrm{~K}$ over 25 month period of observation from an extra tropical latitude $\left(20.8^{\circ} \mathrm{N}\right)$ station, using mesospheric airglow emissions, which is higher in magnitude than ours.

Applying gravity wave Doppler Spread Parameterization (DSP) in a numerical spectral model (NSM) with numerical computation, Mayr et al. (1997) showed global scale seasonal variation in wind field and temperature due to tropospheric gravity wave momentum flux. Their results revealed prominent SAO above $40 \mathrm{~km}$ region and found peak amplitude around $\sim 50 \mathrm{~km}$ with a downward vertical phase speed of $\sim 9 \mathrm{~km} / \mathrm{month}$, which matches closely with our observed ones. The asymmetry in the SAO peak amplitude (higher spring amplitude than fall one) in our present observation from the SABER data shows resemblance with the past observation carried out in the mesospheric temperature data (Taylor et al., 2005).

From the existing literatures it is evident that the higher SAO amplitude compared to the AnO is generally observed at low-latitude sites and the opposite behavior is expected at mid-latitude locations (Shepherd et al., 2004; Xu et al., 2007; Gelinas et al., 2008). Less dominance of the SAO amplitude at higher altitude, as depicted in the present study is unexpected, but not impossible because of regional anomaly or complex wave interaction. In this context, it should be mentioned that Gelinas et al. (2008) also found this unusual phenomenon in few cases during airglow observations 
through $\mathrm{OH}$ and $\mathrm{O}_{2}$ lines intensity and temperature at low and mid latitudes.

\section{Conclusions}

Present long-term temperature observation (1998-2008) using ground based and satellite based instruments, have unveiled prominent features of the $\mathrm{SAO}$ and $\mathrm{AnO}$ in mesosphere-stratosphere dynamical coupled system. The SABER data is found to be extremely good as a proxy for studying atmospheric wave activities along with ground based instruments. Our results indicate agreement in comparison with the past observations in the behavior of the SAO and $\mathrm{AnO}$ and express the need of further study in this regard. Amplitude and phase of the observed SAO and AnO for our site, Gadanki $\left(13.5^{\circ} \mathrm{N}\right)$ are considered to be less affected by the equatorial diurnal tide. Planetary scale waves with greater effect at higher altitude are supposed to be few of the most important contributors for modifying such kind of long-period oscillation signatures. Although exact mechanism of influencing such kind of oscillation activities is still not properly understood, more coordinated systematic temperature as well as wind measurements can give sufficient insight to these less explored unique wave phenomena.

Acknowledgements. Authors gratefully acknowledge the assistance of National Atmospheric Research Laboratory (NARL), Gadanki, India by providing very useful lidar data. A. Guharay sincerely acknowledges the support of Aryabhatta Research Institute of observational scienES (ARIES), Nainital, India to the present research work. A. Guharay is also thankful to Biman Medhi, Orchid Medhi and Manas Samal for their constant moral support. Authors are thankful to the editor and two anonymous reviewers for their useful comments/suggestions, which have enriched the manuscript quality.

Topical Editor C. Jacobi thanks two anonymous referees for their help in evaluating this paper.

\section{References}

Clancy, R. T., Rusch, D. W., and Callan, M. T.: Temperature minima in the average thermal structure of the middle atmosphere (70-80 km) from analysis of 40- to 92-km SME global temperature profiles, J. Geophys. Res., 99, 19001-19020, 1994.

Forbes, J. M. and Gillette, D. F.: A compendium of theoretical atmospheric tidal structures, Part 1, Model description and explicit structures due to realistic thermal and gravitational excitation, Project 6690, Rep. AFGL-TR-82-0173, Air Force Geophys. Lab., Bedford, Mass., 1982.

Gelinas, L. J., Hecht, J. H., Walterscheid, R. L., Roble, R. G., and Woithe, J. M.: A seasonal study of mesospheric temperatures and emission intensities at Adelaide and Alice Springs, J. Geophys. Res., 113, A01304, doi:10.1029/2007JA012587, 2008.

Groves, G. V.: Annual and semi-annual zonal wind components and corresponding temperature and density variations, $60-130 \mathrm{~km}$, Planet. Space Sci., 20, 2099-2112, 1972.
Guharay, A., Taori, A., and Taylor, M.: Summer-time nocturnal wave characteristics in mesospheric $\mathrm{OH}$ and $\mathrm{O}_{2}$ airglow emissions, Earth Planets Space, 60, 973-979, 2008.

Guharay, A., Nath, D., Pant, P., Pande, B., Russell III, J. M., and Pandey, K.: Middle atmospheric thermal structure obtained from Rayleigh lidar and TIMED/SABER observations: A comparative study, J. Geophys. Res., 114, D18105, doi:10.1029/2009JD011963, 2009.

Gurubaran, S. and Rajaram, R.: Mean winds, tides, and gravity waves during the westward phase of the mesopause semiannual oscillation (MSAO), J. Geophys. Res., 106(23), 31817-31824, 2001.

Hauchecorne, A. and Chanin, M. -L.: Density and temperature profiles obtained by lidar between 30 and $70 \mathrm{~km}$, Geophys. Res. Lett., 7, 565-568, 1980.

Hirota, I.: Equatorial waves in the upper stratosphere and mesosphere in relation to the semiannual oscillation of the zonal wind, J. Atmos. Sci., 35, 714-722, 1978.

Kishore Kumar, G., Venkat Ratnam, M., Patra, A. K., Vijaya Bhaskara Rao, S., and Russell, J.: Mean thermal structure of the low-latitude middle atmosphere studied using Gadanki Rayleigh lidar, Rocket, and SABER/TIMED observations, J. Geophys. Res., 113, D23106, doi:10.1029/2008JD010511, 2008.

Mayr, H. G., Mengel, J. G., Hines, C. O., Chan, K. L., Arnold, N. F., Reddy, C. A., and Porter, N. S.: The gravity wave Doppler spread theory applied in a numerical spectral model of the middle atmosphere: 2. Equatorial oscillations, J. Geophys. Res., 102, 26093-26105, 1997.

Mertens, C. J., Schmidlin, F. J., Goldberg, R. A., et al.: SABER observations of mesospheric temperatures and comparisons with falling sphere measurements taken during the 2002 summer MaCWAVE campaign, Geophys. Res. Lett., 31, L03105, doi:10.1029/2003GL018605, 2004.

Ratnam, M. V., Kumar, G. K., Murthy, B. V. K., Patra, A. K., Rao, V. V. M. J., Rao, S. V. B., Kumar, K. K., and Ramkumar, G.: Long-term variability of the low latitude mesospheric SAO and QBO and their relation with stratospheric QBO, Geophys. Res. Lett., 35, L21809, doi:10.1029/2008GL035390, 2008.

Reed, R. J.: The quasi-biennial oscillation of the atmosphere between 30 and $50 \mathrm{~km}$ over Ascension Island, J. Atmos. Sci., 22 331-333, 1965.

Remsberg, E. E., Marshall, B. T., Garcia-Comas, M., et al.: Assessment of the quality of the version 1.07 temperature-versus-pressure profiles of the middle atmosphere from TIMED/SABER, J. Geophys. Res., 113, D17101, doi:10.1029/2008JD010013, 2008.

Russell III, J. M., Mlynczak, M. G., Gordley, L. L., Tansock, J., and Esplin, R.: An overview of the SABER experiment and preliminary calibration results, in Proceedings of the SPIE, 44th Annual Meeting, Denver, Colorado, 18-23 July, vol. 3756, pp. 277-288, 1999.

Shepherd, M. G., Evans, W. F. J., Hernandez, G., Offermann, D., and Takahashi, H.: Global variability of mesospheric temperature: Mean temperature field, J. Geophys. Res., 109, D24117, doi:10.1029/2004JD005054, 2004.

Shepherd, M. G., Shepherd, G. G., Evans, W. F. J., and Sridharan, S.: Global variability of mesospheric temperature: Planetaryscale perturbations at equatorial and tropical latitudes, J. Geophys. Res., 110, D24103, doi:10.1029/2005JD006128, 2005. 
Siva Kumar, V., Rao, P. B., and Krishnaiah, M.: Lidar measurements of stratosphere-mesosphere thermal structure at a low latitude: Comparison with satellite data and models, J. Geophys. Res., 108(D11), 4342, doi:10.1029/2002JD003029, 2003.

Taylor, M. J., Taori, A. K., Hatch, D. R., Liu, H. L., and Roble, R. G.: Characterization of the semi-annual-oscillation in mesospheric temperatures at low-latitudes, Adv. Space Res., 35, 2037-2043, 2005.
Xu, J., Smith, A. K., Yuan, W., Liu, H.-L., Wu, Q., Mlynczak, M. G., and Russell III, J. M.: Global structure and long-term variations of zonal mean temperature observed by TIMED/SABER, J. Geophys. Res., 112, D24106, doi:10.1029/2007JD008546, 2007.

Zhao, Y., Taylor, M. J., Liu, H.-L., and Roble, R. G.: Seasonal oscillations in mesospheric temperatures at low-latitudes, J. Atmos. Solar Terr. Phys., 69, 2367-2378, 2007. 